\title{
PtCo alloy nanoparticles supported on graphene nanosheets with high performance for methanol oxidation
}

\author{
HUANG HuaJie, SUN DongPing \& WANG Xin * \\ Key Laboratory of Soft Chemistry and Functional Materials of the Ministry of Education, Nanjing University of Science and Technology, Nanjing \\ 210094, China
}

Received December 23, 2011; accepted May 3, 2012; published online June 26, 2012

\begin{abstract}
PtCo alloy nanoparticles are deposited onto graphene sheets through a facile and reproducible hydrothermal method. During the hydrothermal reaction, the reduction of graphene oxide and PtCo alloy nanoparticles loading can be achieved. X-ray diffraction (XRD) analyses reveal a good crystallinity of the supported Pt nanoparticles in the composites and the formation of PtCo alloy. X-ray photoelectron spectra (XPS) results depict that Pt mainly exists in the metallic form, while much of the cobalt is oxidized. Transmission electron microscope (TEM) observations show that the PtCo alloy nanoparticles are uniformly dispersed on graphene nanosheets compared with multiwalled carbon nanotubes (MWNTs). This PtCo-graphene composite exhibits excellent electrocatalytic activity and high poison tolerance toward poisoning species for methanol oxidation reaction, far outperforming the Pt-graphene or PtCo-MWNTs composites with the same feeding ratio of Pt/carbon.
\end{abstract}

graphene, PtCo alloy nanoparticles, electrocatalyst, methanol oxidation, fuel cells

Citation: Huang H J, Sun D P, Wang X. PtCo alloy nanoparticles supported on graphene nanosheets with high performance for methanol oxidation. Chin Sci Bull, 2012, 57: 3071-3079, doi: 10.1007/s11434-012-5327-4

In order to satisfy mankind's ever-increasing energy needs and address the escalating environmental problems, the use of alternative energy sources to replace the currently dominant fossil fuels will be necessary in the future $[1,2]$. Thus great efforts have been made to explore sustainable energy systems such as fuel cells $[3,4]$. Among various kinds of fuel cells, direct methanol fuel cells (DMFCs) are a promising power generator because of their high-energy conversion efficiency, low operating temperature, low pollutant emission, and ease of handling and processing of the liquid fuel [5-7].

Over the past decade, many of researchers have been concentrating on the development of better catalysts for methanol oxidation [6,8]. Metallic platinum is a singlecomponent catalyst that shows a significant activity for methanol oxidation [9]. However, the pure Pt system may be easily poisoned by $\mathrm{CO}$ and the high cost limits its application as electrocatalyst in commercial field [10-12]. To

*Corresponding author (email: wxin@public1.ptt.js.cn) overcome these problems, several studies have been carried out to design and synthesize Pt-based alloy electrocatalysts resulting in a better electrocatalytic performance and a lowered Pt content [13-15]. Up to date, bimetallic PtRu has been considered to be the most active catalyst mainly due to the bi-functional mechanism and the ligand (electronic) effect $[8,9,16]$. Nevertheless, the supply of Ru and the toxicological effect of Ru remain questionable [17]. Therefore, research on less expensive alloy that mixes Pt with nonprecious metals has been undertaken [17-21]. Among these different non-noble metal alloy catalysts, PtCo alloy was found to be a better catalyst for methanol oxidation under the commonly used acidic conditions [17,19,22]. The remarkable enhancement in electrocatalytic activities on PtCo systems can be attributed to two mechanisms: (1) as cobalt is more electropositive than platinum, Pt could withdraw electrons from the neighboring cobalt atoms, leading to promotion of the $\mathrm{C}-\mathrm{H}$ cleavage reaction; (2) the presence of cobalt oxide provides an oxygen source for $\mathrm{CO}$ oxidation at lower potentials $[19,21]$. 
Since the first report in 2004, graphene has attracted tremendous attention from both the experimental and theoretical scientific communities due to its outstanding mechanical, thermal, electrical, and optical properties and extremely high specific surface area $\left(2600 \mathrm{~m}^{2} \mathrm{~g}^{-1}\right)$ [23-27]. In view of the unique structure of graphene, this two-dimensional (2D) carbon material has found potential applications as a heterogeneous catalyst support in DMFCs [28,29]. It is well known that carbon nanotubes (CNTs) have been extensively studied as supports for the dispersion of Pt nanoparticles owing to their fascinating properties [30-33]. In comparison with CNTs, graphene possesses similar stable physical properties but larger surface areas, which can be considered as an unrolled CNT [34,35]. The combination of Pt nanoparticles and 2D-structure graphene opens up new possibilities for designing the next generation catalysts.

Most recently, some research groups have investigated graphene as catalyst support and have demonstrated that graphene can effectively improve electrocatalytic activity of $\mathrm{Pt}$ or PtRu nanoparticles for methanol oxidation [36-41]. However, relatively little attention has been paid so far to graphene-supported PtCo alloy nanoparticles as anode electrocatalysts for DMFCs. Herein, we demonstrated a facile and reproducible route to obtain $\mathrm{PtCo}$-graphene catalyst via a hydrothermal reaction. The electrochemical properties of as-obtained PtCo-graphene catalyst were systematically investigated, together with Pt-graphene and Pt-multiwalled carbon nanotubes (MWNTs) catalysts for comparison.

\section{Experimental}

\subsection{Materials}

Natural flake graphite with an average particle size of $40 \mu \mathrm{m}$ was purchased from Qingdao Zhongtian Company (Qingdao, China). MWNTs ( $>95 \%$ purity) were purchased from Chengdu organic chemicals Co. Ltd. (Chengdu, China), where the materials were prepared by chemical vapor deposition (CVD). $\mathrm{K}_{2} \mathrm{PtCl}_{4}$ was obtained from Alfa Aesar. $\mathrm{Co}\left(\mathrm{NO}_{3}\right)_{2} \cdot 6 \mathrm{H}_{2} \mathrm{O}$ was purchased from Sinopharm Chemical Reagent Co. Ltd. (Shanghai, China). Nafion 117 was purchased from Dupont. All other chemicals employed were of analytic grade and used as received. All aqueous solutions were prepared using deionized water.

\subsection{Synthesis of PtCo-graphene, Pt-graphene and PtCo-MWNTs composites}

The graphite oxide (GO) was prepared according to a modified Hummers method as described previously [42]. To obtain the PtCo-graphene composite, $10 \mathrm{mg}$ GO were dispersed in $80 \mathrm{~mL}$ of deionized water and sonicated for $1 \mathrm{~h}$, forming stable graphene oxide colloid. Then $0.205 \mathrm{~mL}$ of $0.1 \mathrm{~mol} \mathrm{~L}^{-1} \mathrm{~K}_{2} \mathrm{PtCl}_{4}$ solution, $0.110 \mathrm{~mL}$ of $0.1 \mathrm{~mol} \mathrm{~L}^{-1}$ $\mathrm{Co}\left(\mathrm{NO}_{3}\right)_{2}$ solution and $200 \mathrm{mg} \mathrm{NaBH}{ }_{4}$ were introduced to the solution with magnetic stirring for $15 \mathrm{~min}$. The resulting suspension was transferred into a $100 \mathrm{~mL}$ Teflon-lined stainless steel autoclave and sealed tightly. The autoclave was then heated to $120^{\circ} \mathrm{C}$ and kept there for $24 \mathrm{~h}$. After the hydrothermal treatment, the nanocomposite, labeled as $\mathrm{PtCo} / \mathrm{G}$, was then centrifuged, washed, and finally dried in air at $60^{\circ} \mathrm{C}$ overnight. Similar procedures were used to prepare Pt-graphene composite, the only difference was the absence of $\mathrm{Co}\left(\mathrm{NO}_{3}\right)_{2}$ and the composite was denoted as $\mathrm{Pt} / \mathrm{G}$. For comparison, MWNTs were functionalized by refluxing in nitric acid $(65 \mathrm{wt} \%)$ for $12 \mathrm{~h}$. The acid-treated MWNTs were diluted with water, centrifuged, and dried at $90^{\circ} \mathrm{C}$ overnight. For the synthesis of PtCo-MWNTs nanocomposite with same $\mathrm{Pt}$ contents, $10 \mathrm{mg}$ acid-treated MWNTs were dispersed in $80 \mathrm{~mL}$ of deionized water and sonicated for $1 \mathrm{~h}$. Then $0.205 \mathrm{~mL}$ of $0.1 \mathrm{~mol} \mathrm{~L}^{-1} \mathrm{~K}_{2} \mathrm{PtCl}_{4}$ solution, $0.110 \mathrm{~mL}$ of $0.1 \mathrm{~mol} \mathrm{~L}^{-1} \mathrm{Co}\left(\mathrm{NO}_{3}\right)_{2}$ solution and $200 \mathrm{mg} \mathrm{NaBH}{ }_{4}$ were introduced to the solution with magnetic stirring for $15 \mathrm{~min}$. Subsequently, similar hydrothermal treatment was used and the composite was labeled as $\mathrm{PtCo} / \mathrm{MWNTs}$.

\subsection{Characterization}

Powder X-ray diffraction (XRD) analyses were performed on a Bruker D8 Advance diffractometer with $\mathrm{Cu} \mathrm{K} \alpha$ radiation $(\lambda \approx 1.54 \AA$ ). Raman spectra of all the samples were collected using a Renishaw Raman microscope. X-ray photoelectron spectra (XPS) were recorded on a RBD upgraded PHI-5000C ESCA system (Perkin Elmer) with Al K $\alpha$ radiation $(h v=1486.6 \mathrm{eV})$. Field emission scanning electron microscope (FESEM) images were taken with a LEO-1550 microscopy. Transmission electron microscopy (TEM) images and energy dispersive X-ray (EDX) spectroscopy were performed on a JEOL JEM-2100 microscope operating at $200 \mathrm{kV}$, by depositing a drop of sample dispersion onto 300 mesh $\mathrm{Cu}$ grids coated with a carbon layer.

\subsection{Electrochemical activity measurement}

Electrocatalytic activities of samples were measured in a conventional three electrode cell using a CHI 660B electrochemical workstation. The three-electrode cell consisted of a Pt wire serving as the counter electrode, a saturated calomel electrode (SCE) serving as the reference electrode and a glassy carbon (GC) disk (3 $\mathrm{mm}$ in diameter) with coated catalysts serving as the working electrode. The work electrode was manufactured as follows: the $2 \mathrm{mg}$ of catalyst powder was dispersed in a mixed solution $(500 \mu \mathrm{L}$ of water, $500 \mu \mathrm{L}$ of ethanol and $50 \mu \mathrm{L}$ of $5 \%$ Nafion 117 solution) with ultrasonication for $30 \mathrm{~min}$ to form a homogeneous black suspension. Then $20 \mu \mathrm{L}$ of the resulting suspension was carefully pipetted onto the GC electrode surface, and the coating was dried at room temperature for $1 \mathrm{~h}$. The ECSA values of the catalysts were determined by cyclic 
voltammetry $(\mathrm{CV})$ of the hydrogen absorption/desorption in $1 \mathrm{~mol} \mathrm{~L}^{-1} \mathrm{H}_{2} \mathrm{SO}_{4}$ solution at room temperature. The electrocatalytic activity of the as-prepared catalysts for the methanol oxidation was characterized by collecting $\mathrm{CVs}$ in a $\mathrm{N}_{2}$-purged $1 \mathrm{~mol} \mathrm{~L}^{-1} \mathrm{H}_{2} \mathrm{SO}_{4}$ and $2 \mathrm{~mol} \mathrm{~L}^{-1}$ methanol solution at a scan rate of $20 \mathrm{mV} \mathrm{s}^{-1}$. Several activation scans were performed until reproducible voltammograms were obtained. Only the last voltammograms were used for comparing the catalytic activity of the specified catalysts. The chronoamperometry tests were conducted at $0.5 \mathrm{~V}$ for a period of $30 \mathrm{~min}$. The chronopotentiometric curves were recorded in $1 \mathrm{~mol} \mathrm{~L}^{-1} \mathrm{H}_{2} \mathrm{SO}_{4}$ and $2 \mathrm{~mol} \mathrm{~L}^{-1}$ methanol solution. The value of the applied current was obtained at $0.5 \mathrm{~V}$ from the forward scan of the corresponding cyclic voltammogram.

\section{Results and discussion}

Typical XRD patterns of $\mathrm{GO}, \mathrm{Pt} / \mathrm{G}, \mathrm{PtCo} / \mathrm{G}$ and $\mathrm{PtCo} /$ MWNTs are presented in Figure 1. As can be seen from spectrum 1, the most intensive peak of GO at around $2 \theta=$ $10.5^{\circ}$ corresponds to the $(001)$ reflection and the interlayer spacing $(0.86 \mathrm{~nm})$ was much larger than that of pristine graphite $(0.34 \mathrm{~nm})$ due to the introduction of oxygen-containing functional groups on the graphite sheets [43]. For $\mathrm{Pt} / \mathrm{G}$ composite (spectrum 2), the suppression of the GO peak indicates that GO is further converted to the crystalline graphene, and the conjugated graphene network ( $\mathrm{sp}^{2}$ carbon) has been reestablished due to the reduction process [36]. Meanwhile, the diffraction peaks observed at $39.5^{\circ}, 46.8^{\circ}$ and $67.6^{\circ}$ correspond to the (111), (200) and (220) planes of the face-centered cubic (fcc) structure of Pt, respectively (JCPDS 87-0646). These obvious characteristic peaks indicate a good crystallinity of the supported Pt nanoparticles in the composite. In the case of $\mathrm{PtCo} / \mathrm{G}$ (spectrum 3) and $\mathrm{PtCo} / \mathrm{MWNTs}$ (spectrum 4) catalysts, the Pt diffraction peaks appear to shift to higher angles compared with Pt/G catalyst, indicating the contraction of lattice by the incorporation of

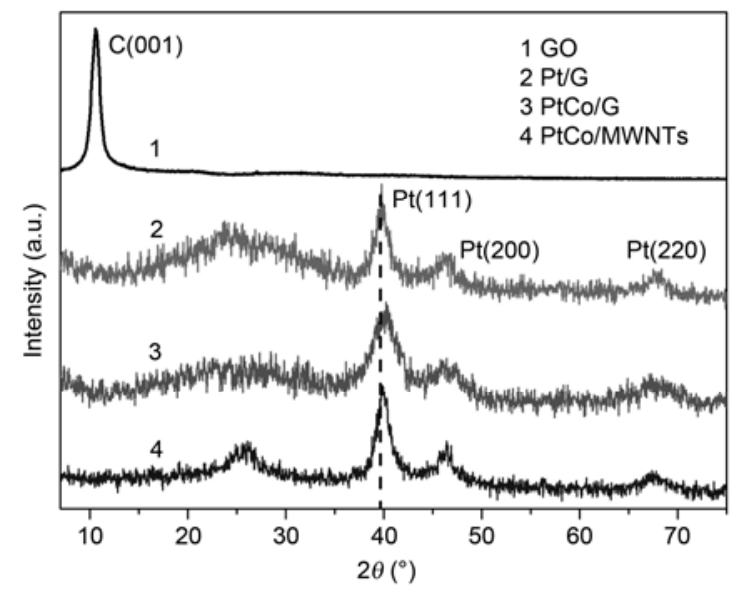

Figure 1 XRD patterns of $\mathrm{GO}, \mathrm{Pt} / \mathrm{G}, \mathrm{PtCo} / \mathrm{G}$ and $\mathrm{PtCo} / \mathrm{MWNTs}$. metal $\mathrm{Co}$ in the fcc structure of Pt due to alloy formation [44]. No peaks for pure Co or its oxides were observed, but their presence cannot be discarded because they may be present in a very small amount or even in an amorphous form [19].

Raman spectroscopy is a widely used tool for the characterization of carbon products. Figure 2 displays Raman spectra of GO, Pt/G, PtCo/G and PtCo/MWNTs. The typical features for GO in spectrum 1 are the $\mathrm{G}$ band at $\sim 1570$ $\mathrm{cm}^{-1}$ and $\mathrm{D}$ band at $\sim 1350 \mathrm{~cm}^{-1}$. The $\mathrm{G}$ band is usually assigned to the stretching mode of crystal graphite, while the $\mathrm{D}$ band corresponds to the poor crystallization of graphite [45]. For Pt/G and PtCo/G composites, the $\mathrm{G}$ and $\mathrm{D}$ bands shift towards lower frequencies in comparison with that of GO, indicating the reduction of GO $[46,47]$. Furthermore, the increased D/G intensity ratio in spectrum 2 and 3 suggests a decrease in the average size of the $\mathrm{sp}^{2}$ domains upon reduction of the exfoliated $\mathrm{GO}$, and it can be explained if new graphitic domains were created that are smaller in size than ones present in GO [46,48]. Additionally, as displayed in the inset of Figure 2, the 2D band of $\mathrm{PtCo} / \mathrm{G}$ at $2690 \mathrm{~cm}^{-1}$ is also observed, which is similar to that of monolayer graphene $[49,50]$. In combination with the XRD results, it can be deduced that a remarkably small amount of multilayer carbon sheets is present in $\mathrm{PtCo} / \mathrm{G}$ composite. In spectrum 4, $\mathrm{PtCo} / \mathrm{MWNTs}$ composite exhibits a $\mathrm{D}$ band with much lower intensity, mainly due to the fact that the acid-treatment processes of MWNTs are much softer when compared with the oxidation processes of graphite.

It is known that graphene can be obtained through various physical and chemical routes, including the removal of the oxygen from graphene oxide sheets via hydrothermal reaction in the presence of reducing agents. As shown in Figure 3(a) and (b), the O/C ratio in the as-synthesized $\mathrm{PtCo} / \mathrm{G}$ composite decreases remarkably after hydrothermal reaction, and that most of the oxygen-containing functional groups were successfully removed. These results, combined with

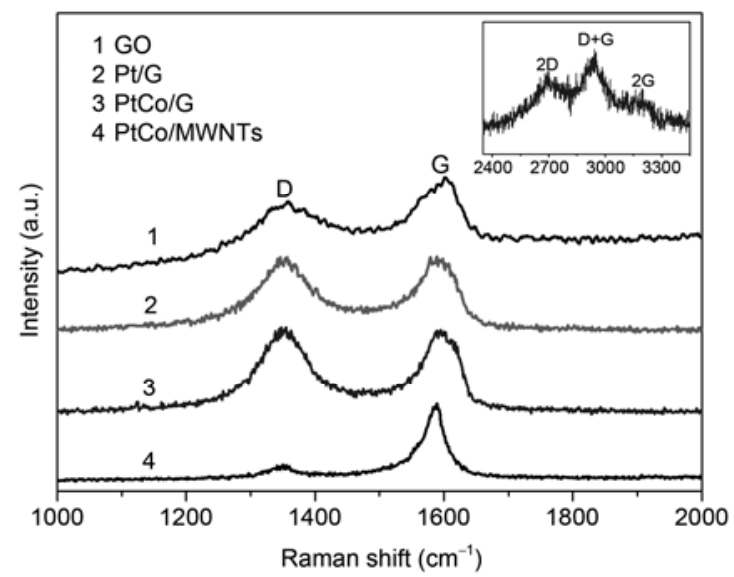

Figure 2 Raman spectra of $\mathrm{GO}, \mathrm{Pt} / \mathrm{G}, \mathrm{PtCo} / \mathrm{G}$ and $\mathrm{PtCo} / \mathrm{MWNTs}$. The inset shows the characteristic $2 \mathrm{D}$ band of $\mathrm{PtCo} / \mathrm{G}$. 

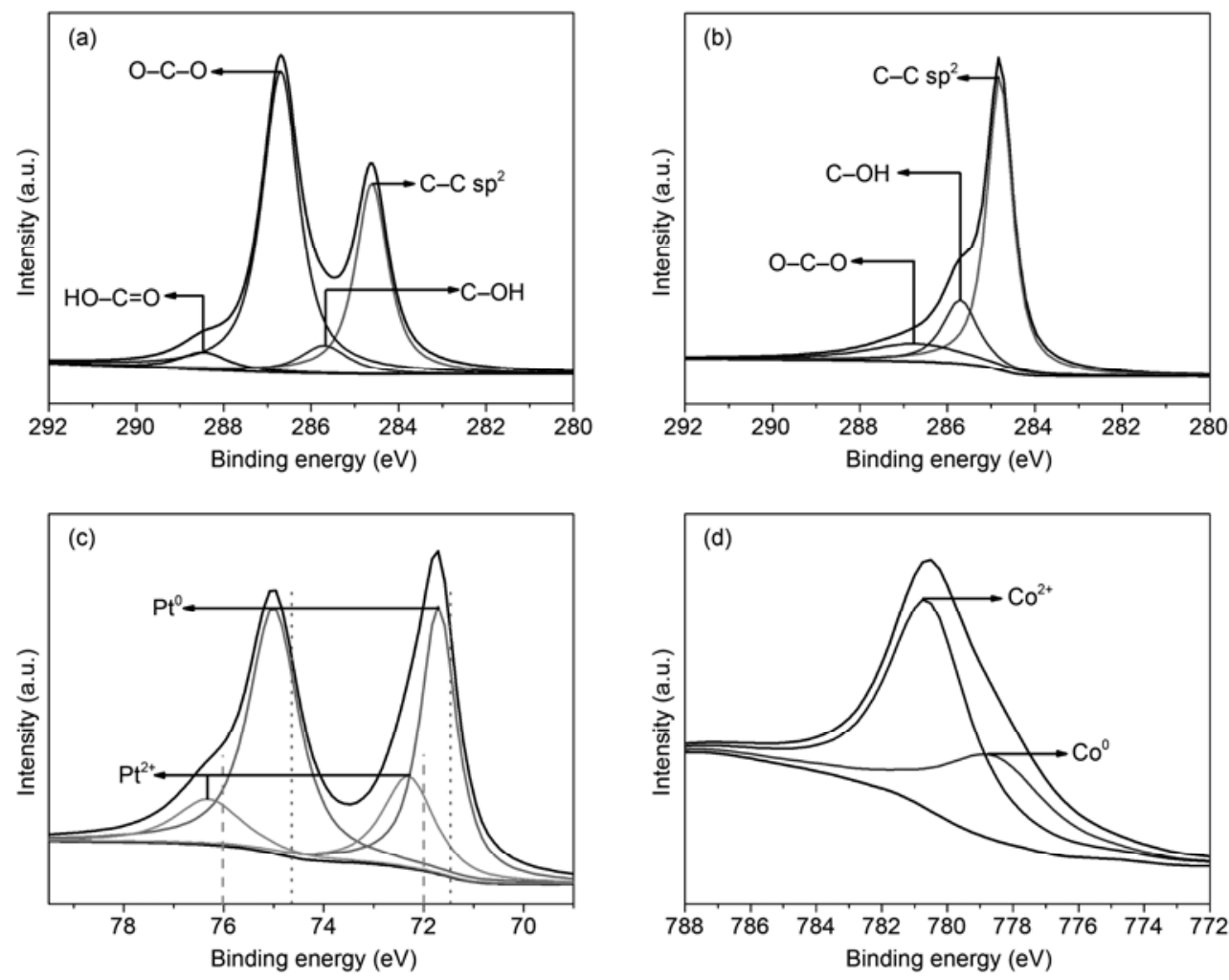

Figure $3 \mathrm{C}$ 1s core-level XPS spectra of (a) GO and (b) PtCo/G; (c) Pt 4f and (d) Co 2p $\mathrm{p}_{3 / 2}$ core-level XPS spectra of PtCo/G, the dotted lines are the Pt 4f peak positions for pure Pt.

the XRD and Raman analysis, further confirm the formation of graphene. Furthermore, XPS studies also show that there are different $\mathrm{Pt}$ or Co oxidation states in the catalyst. As can be seen from Figure 3(c), the Pt 4f signal of $\mathrm{PtCo} / \mathrm{G}$ consists of two pairs of doublets: the most intense doublet (71.6 and $74.9 \mathrm{eV})$ corresponds to metallic $\mathrm{Pt}$; the second set of doublets $(72.2$ and $76.2 \mathrm{eV})$ can be assigned to the +2 oxidation state of $\mathrm{Pt}[12,51]$. It is clearly seen that the Pt $4 \mathrm{f}$ core-levels for $\mathrm{PtCo} / \mathrm{G}$ are shifted to higher binding energies with respect to pure Pt, which can be ascribed to the $5 \mathrm{~d}$ electron loss in Pt-based alloy systems [52]. However, in view of the electronegativity difference between Co and Pt (1.8 and 2.2, respectively), it should be noted that the electron transfer must occur from Co to Pt. According to previous theoretical studies, when the Pt atom is alloyed with a second component, it has been demonstrated the total number of electrons per $\mathrm{Pt}$ atom increases while the $5 \mathrm{~d}$ electron decreases $[53,54]$. Figure $3(d)$ presents the curve-fitted Co $2 p_{3 / 2}$ spectrum for $\mathrm{PtCo} / \mathrm{G}$, which could be deconvoluted into the two peaks with oxidized $\mathrm{Co}$ as the predominant specie. This contrasts strongly with $\mathrm{Pt}$, where the metallic state predominates. These results can be linked to the electron-withdrawing effect from Pt to the neighbouring Co atoms, making the latter more difficult to be reduced [17].

The heterostructures of the as-obtained composites can be verified by the morphological analyses. Figure 4(a) and (b) present the typical FESEM images of $\mathrm{Pt} / \mathrm{G}$ and $\mathrm{PtCo} / \mathrm{G}$ composites, respectively. It is clearly seen from Figure 4(a) that the almost transparent graphene sheets were decorated uniformly by the nanoscale $\mathrm{Pt}$ particles. In the case of $\mathrm{PtCo} / \mathrm{G}$ composite (Figure 4(b)), the sizes of PtCo alloy particles are larger than those of $\mathrm{Pt}$ particles in $\mathrm{Pt} / \mathrm{G}$. This result is in agreement with the previous reports $[19,55]$. Similar observations were made with TEM. As shown in Figure 4(c), few nanoparticles scattered out of the supports, suggesting the strong interaction between Pt nanoparticles and the carbon substrates. Meanwhile, the $d$-spacing value of $0.22 \mathrm{~nm}$ coincides with that of face centered cubic (fcc) Pt (111) [37]. In Figure 4(d), it is evident that the particle size distribution is slightly broader in the case of the alloy catalyst with a significant fraction of particles larger than $10 \mathrm{~nm}$. Moreover, it can be found that the PtCo alloy particles deposited on MWNTs tend to form aggregates (Figure 4(e)), which is probably caused by the relatively smaller specific area of MWNTs. The size distributions were obtained by measuring the sizes of 100 randomly selected particles in the magnified TEM images. The average particle sizes were about 4.4, 9.1 and $15.9 \mathrm{~nm}$ for $\mathrm{Pt} / \mathrm{G}, \mathrm{PtCo} / \mathrm{G}$ and $\mathrm{PtCo} / \mathrm{MWNTs}$, respectively. In addition, EDX spectrum obtained from $\mathrm{PtCo} / \mathrm{G}$ composite in Figure 4(f) shows distinct Pt and Co peaks, further confirming the presence of both the Pt and Co metal in the composite.

On the basis of above experimental results, a mechanism to interpret the formation of as-obtained $\mathrm{PtCo} / \mathrm{G}$ nanocomposites 

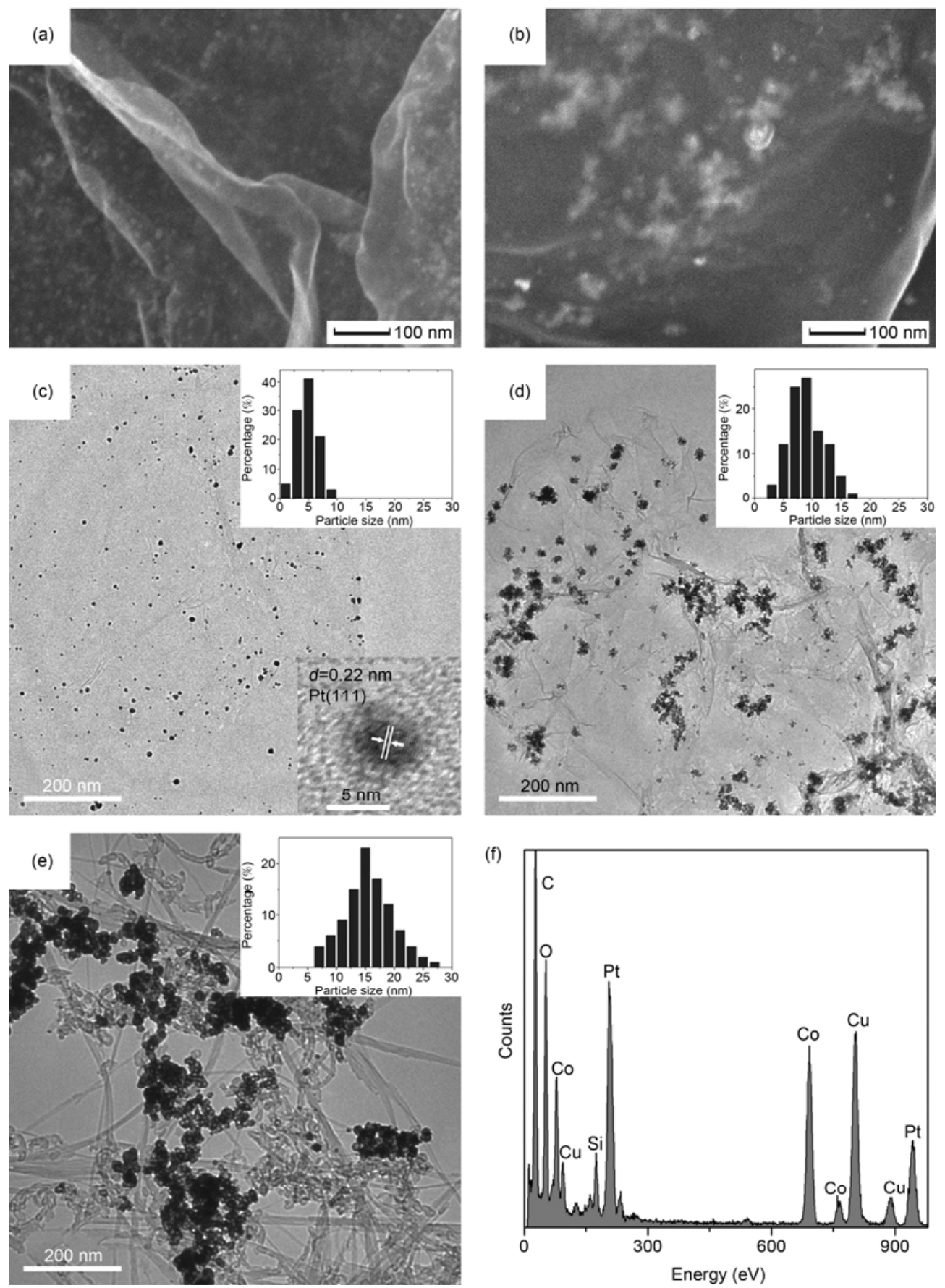

Figure 4 FESEM images of (a) Pt/G and (b) PtCo/G; TEM images and histograms of particle size distribution of (c) Pt/G, (d) PtCo/G and (e) PtCo/ MWNTs, the inset of (c) is an HETEM image of PtCo/G; (f) EDX spectrum of PtCo/G.

is proposed, as shown in Figure 5. For the first stage, natural flake graphite was initially oxidized to GO via a modified Hummer's method, and the interlayer spacing increased from 0.34 to $0.86 \mathrm{~nm}$ due to the introduction of oxygencontaining functional groups. And then GO can be readily exfoliated as individual graphene oxide sheets by ultrasonication in water. During the hydrothermal reaction, the negative charged groups on graphene oxide sheets can act as anchor sites, enable the subsequent in situ formation of nanostructures attaching on the surfaces and edges of graphene oxide sheets. Furthermore, the results of XRD, XPS and Raman measurements (Figures 1-3) indicate that the reduction of graphene oxide is indeed achieved in the presence of $\mathrm{NaBH}_{4}$. Finally, the graphene sheets were successfully decorated by well-dispersed PtCo alloy nanoparticles.

The electrochemically active surface area (ECSA) of an electrocatalyst not only can determine the number of catalytically active sites available for an electrochemical reaction, 


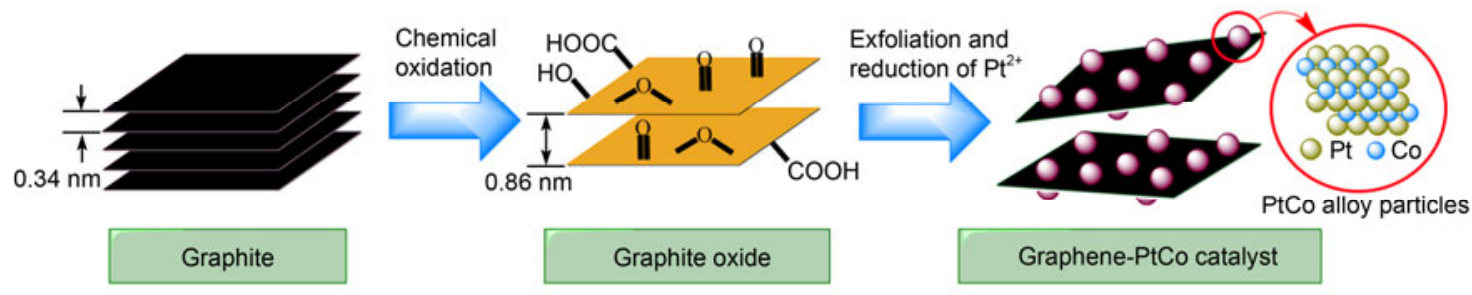

Figure 5 Illustration of the formation process of graphene-PtCo catalyst.

but also account for the access of a conductive path available to transfer electrons to and from the electrode surface $[36,41]$. The $\mathrm{CV}$ curves of $\mathrm{Pt} / \mathrm{G}, \mathrm{PtCo} / \mathrm{G}$ and $\mathrm{PtCo} / \mathrm{MWNTs}$ are presented in Figure 6(a). ECSA values can be calculated from the coulombic charge for the hydrogen adsorption and desorption $\left(Q_{\mathrm{H}}\right)$ in the negative-going potential scan (0 to $-0.2 \mathrm{~V}$ vs SCE) according to the following formula [56]:

$$
\operatorname{ECSA}=\frac{Q_{\mathrm{H}}}{[\mathrm{Pt}] \times 0.21},
$$

where $[\mathrm{Pt}]$ represents the platinum loading $\left(\mathrm{g} \mathrm{cm}^{-2}\right)$ in the
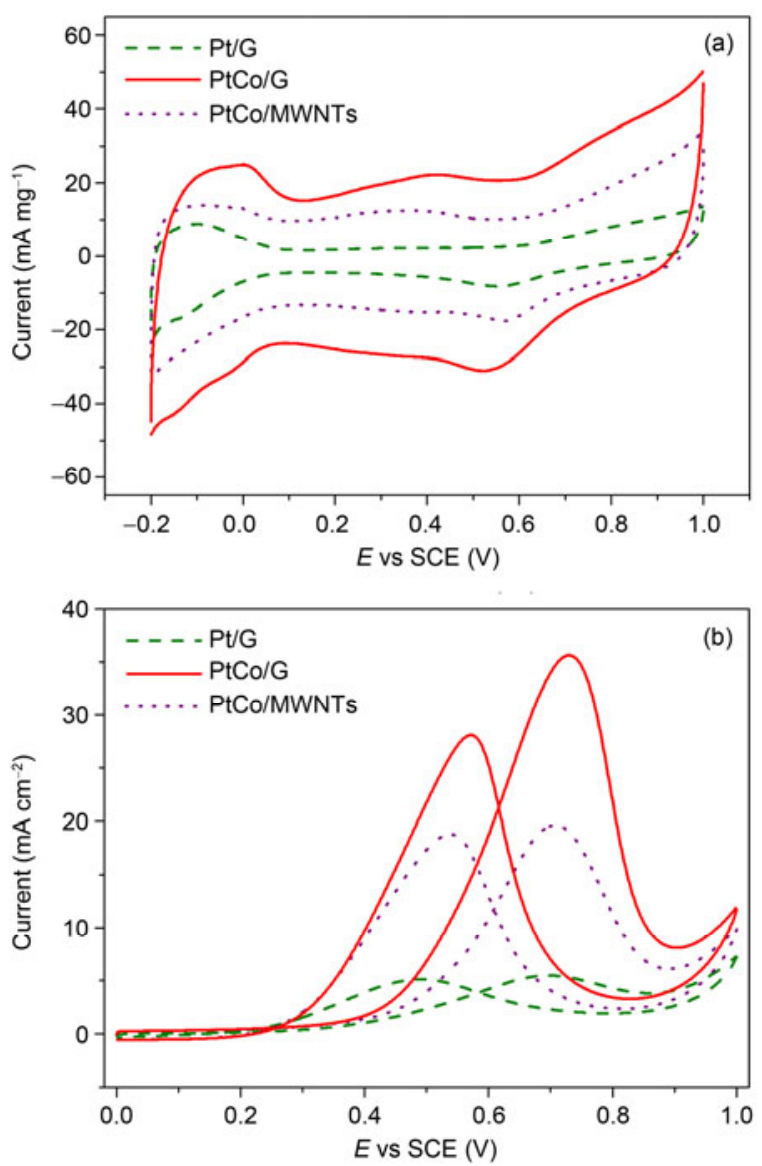

Figure 6 (a) $\mathrm{CVs}$ of $\mathrm{Pt} / \mathrm{G}, \mathrm{PtCo} / \mathrm{G}$ and $\mathrm{PtCo} / \mathrm{MWNTs}$ in $1 \mathrm{~mol} \mathrm{~L}^{-1} \mathrm{H}_{2} \mathrm{SO}_{4}$ solution at a scan rate of $20 \mathrm{mV} \mathrm{s}^{-1}$ between -0.2 and $1.0 \mathrm{~V}$ vs SCE. (b) $\mathrm{CV}$ s of $\mathrm{Pt} / \mathrm{G}, \mathrm{PtCo} / \mathrm{G}$ and $\mathrm{PtCo} / \mathrm{MWNT}$ in $1 \mathrm{~mol} \mathrm{~L}^{-1} \mathrm{H}_{2} \mathrm{SO}_{4}$ and $2 \mathrm{~mol} \mathrm{~L}^{-1}$ methanol solution at a scan rate of $20 \mathrm{mV} \mathrm{s}^{-1}$ between 0 and $1.0 \mathrm{~V}$ vs SCE. electrode, $Q_{\mathrm{H}}$ is the charge for hydrogen desorption (mC $\mathrm{cm}^{-2}$ ), and 0.21 represents the charge required to oxidize a monolayer of $\mathrm{H}_{2}$ on bright $\mathrm{Pt}\left(\mathrm{mC} \mathrm{cm}^{-2}\right)$. The calculated results show that $\mathrm{PtCo} / \mathrm{G}$ exhibits a much higher ECSA value $\left(75.8 \mathrm{~m}^{2} \mathrm{~g}^{-1}\right)$ than $\mathrm{Pt} / \mathrm{G}\left(32.4 \mathrm{~m}^{2} \mathrm{~g}^{-1}\right)$ (Table 1), clearly demonstrating that $\mathrm{PtCo} / \mathrm{G}$ possesses much higher electrochemical activity than $\mathrm{Pt} / \mathrm{G}$. This is because that the presence of cobalt atoms in the composite places $\mathrm{Pt}$ in a more reduced state than in the absence of $\mathrm{Co}$, which is beneficial to the initiation of methanol dehydrogenation and promotion of the electrochemical activity. Furthermore, when MWNTs served as a supporting material, the ECSA value of the catalyst was only $50.1 \mathrm{~m}^{2} \mathrm{~g}^{-1}$, much less competitive than that of graphene, due to the poor dispersion of PtCo alloy nanoparticles on MWNTs surface.

The electrocatalytic activities of as-synthesized Pt/G, $\mathrm{PtCo} / \mathrm{G}$ and $\mathrm{PtCo} / \mathrm{MWNTs}$ catalysts for methanol oxidation reaction in acid medium were studied by cyclic voltammetry. As shown in Figure 6(b), there are two irreversible current peaks during the electrooxidation of methanol that are typically attributed on the forward scan peak at around $0.7 \mathrm{~V}$ to the oxidation of methanol and on the reverse scan peak at around $0.5 \mathrm{~V}$, to the removal of the incompletely oxidized carbonaceous species (such as $\mathrm{CO}$ ) formed during the forward scan [16]. The values of the forward anodic peak current density for different catalysts follow the same trend as those for ECSA with $\mathrm{PtCo} / \mathrm{G}>\mathrm{PtCo} / \mathrm{MWNTs}>\mathrm{Pt} / \mathrm{G}$. The peak current density of the forward scan is associated with the oxidation of methanol and therefore $\mathrm{PtCo} / \mathrm{G}$ has the best electrocatalytic activity among these catalysts. The ratio of the forward anodic peak current density $\left(I_{\mathrm{F}}\right)$ to the reverse anodic peak current density $\left(I_{R}\right)$ can be employed to evaluate catalyst tolerance to accumulation of intermediate poisoning species on the electrode surface. A higher ratio indicates more effective removal of the poisoning species on the catalyst surface [41]. As listed in Table 1 , the $I_{\mathrm{F}} / I_{\mathrm{R}}$ values

Table 1 Compiled study comparing CV results for different carbon-based samples

\begin{tabular}{lcccc}
\hline \multicolumn{1}{c}{ Electrode } & ECSA $\left(\mathrm{m}^{2} \mathrm{~g}^{-1}\right)$ & $I_{\mathrm{F}}\left(\mathrm{mA} \mathrm{cm}^{-2}\right)$ & $I_{\mathrm{R}}\left(\mathrm{mA} \mathrm{cm}^{-2}\right)$ & $I_{\mathrm{F}} / I_{\mathrm{R}}$ ratio \\
\hline $\mathrm{Pt} / \mathrm{G}$ & 32.4 & 5.4 & 5.0 & 1.08 \\
$\mathrm{PtCo} / \mathrm{G}$ & 75.8 & 35.8 & 28.0 & 1.28 \\
$\mathrm{PtCo} / \mathrm{MWNTs}$ & 50.1 & 19.6 & 18.9 & 1.04 \\
\hline
\end{tabular}


for $\mathrm{Pt} / \mathrm{G}, \mathrm{PtCo} / \mathrm{G}$ and $\mathrm{PtCo} / \mathrm{MWNTs}$ were calculated to be 1.08, 1.28 and 1.04, respectively. The better antipoisoning ability of $\mathrm{PtCo} / \mathrm{G}$ for methanol oxidation can be not only attributed to cobalt oxide component which provides more sufficient oxygen source for oxidation of carbonaceous species, but also to the high dispersion of PtCo alloy nanoparticles on graphene sheets.

For the practical applications, it is of great importance to improve the durability of electrodes. The long-term electrocatalytic activities and stabilities of $\mathrm{Pt} / \mathrm{G}, \mathrm{PtCo} / \mathrm{G}$ and $\mathrm{PtCo} /$ MWNTs were examined by chronoamperometry for methanol oxidation at $0.5 \mathrm{~V}$. As displayed in Figure 7(a), the currents of all catalysts decreased rapidly at the initial stage, supposedly because of catalyst poisoning by chemisorbed intermediate carbonaceous species formed during the methanol oxidation reaction [37]. Then the currents gradually decayed and a pseudosteady state was achieved. After 2000 s of polarization, $\mathrm{PtCo} / \mathrm{G}$ still exhibited the highest current density among all the catalysts, confirming its best electrocatalytic performance. The results can be linked to the smaller fine PtCo alloy particles and the synergistic effect of the bimetallic active components in the $\mathrm{PtCo} / \mathrm{G}$ catalyst.

Figure 7(b) shows the chronopotentiometric curves of
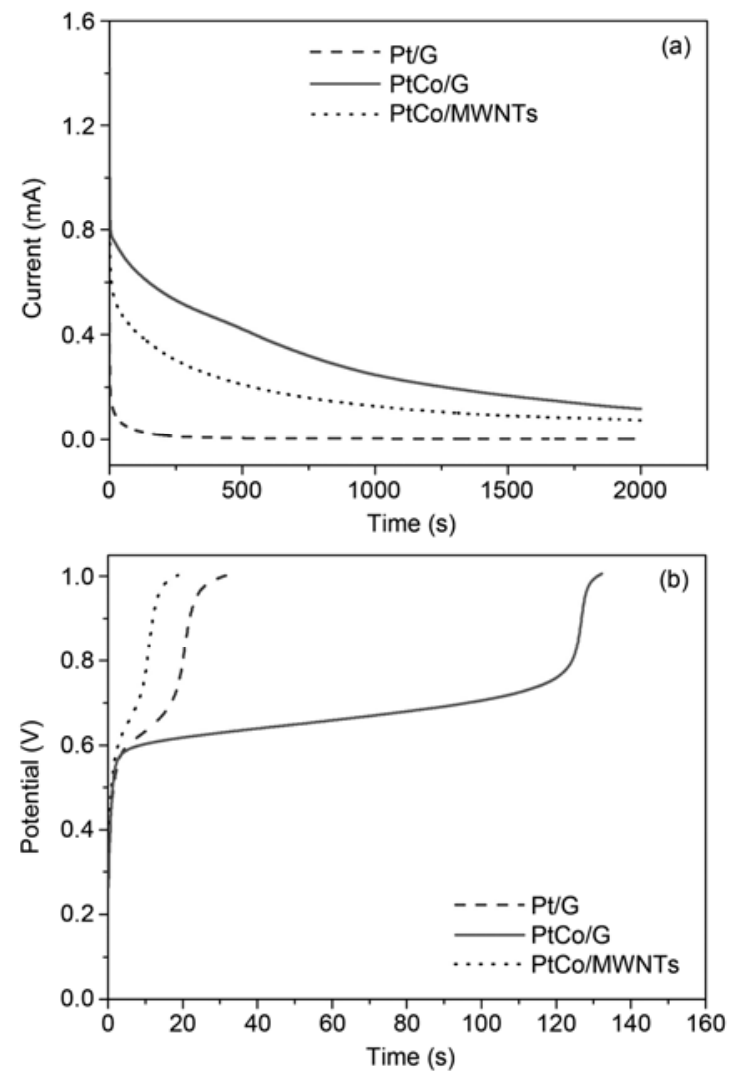

Figure 7 (a) Chronoamperometric response recorded at $0.5 \mathrm{~V}$ (vs SCE) in $1 \mathrm{~mol} \mathrm{~L}^{-1} \mathrm{H}_{2} \mathrm{SO}_{4}$ and $2 \mathrm{~mol} \mathrm{~L}^{-1}$ methanol solution for $\mathrm{Pt} / \mathrm{G}, \mathrm{PtCo} / \mathrm{G}$ and $\mathrm{PtCo} / \mathrm{MWNTs}$. (b) Chronopotentiometric curves of $\mathrm{Pt} / \mathrm{G}, \mathrm{PtCo} / \mathrm{G}$ and $\mathrm{PtCo} /$ MWNTs in $1 \mathrm{~mol} \mathrm{~L}^{-1} \mathrm{H}_{2} \mathrm{SO}_{4}$ and $2 \mathrm{~mol} \mathrm{~L}^{-1}$ methanol solution.
$\mathrm{Pt} / \mathrm{G}, \mathrm{PtCo} / \mathrm{G}$ and PtCo/MWNTs catalysts. To diminish the influence of electrocatalytic activity of catalysts to the utmost extent, the value of the applied anodic current density is the same as that of the current density at $0.5 \mathrm{~V}$ on the forward branch of the corresponding cyclic voltammogram. As displayed in Figure 7(b), the electrode potential increases gradually at first and then instantaneously reaches to a much higher potential for all catalysts. This is due to the fact that during the chronopotentiometric experiment, the carbonaceous residues are accumulated on the surface of electrocatalysts, leaing to a lower electrocatalytic activity of catalysts [57]. Thus the potential must increase to satisfy the applied current until a potential is reached where larger amounts of $\mathrm{H}_{2} \mathrm{O}$ can be decomposed [58]. The time at which the electrode potential jumps to a higher potential can be used to judge the antipoisoning ability of catalysts [59]. Obviously, the sustained time for these catalysts decreases in the order $\mathrm{PtCo} / \mathrm{G}(\sim 120 \mathrm{~s})>\mathrm{Pt} / \mathrm{G}(\sim 20 \mathrm{~s})>\mathrm{PtCo} / \mathrm{MWNTs}(\sim 10 \mathrm{~s})$, consistenting with the $I_{\mathrm{F}} / I_{\mathrm{R}}$ values based on CV tests. Additionally, before the potential jumps, the lowest potential level can be observed on $\mathrm{PtCo} / \mathrm{G}$ electrode. These results further suggest that the $\mathrm{PtCo} / \mathrm{G}$ catalyst has the best electrocatalytic activity and antipoisoning ability among the three catalysts.

\section{Conclusions}

In summary, PtCo alloy nanoparticles have been successfully loaded on graphene nanosheets via a simple and reproducible hydrothermal method. The as-synthesized composites were characterized by XRD, Raman, XPS, morphology analyses and electrochemical tests. It has been found that $\mathrm{PtCo} / \mathrm{G}$ has better electrocatalytic activity and stability than $\mathrm{Pt} / \mathrm{G}$ or PtCo/MWNTs for methanol oxidation, which can be not only attributed to the synergistic effect of the bimetallic active components, but also to the high dispersion of PtCo alloy nanoparticles on graphene surface. With further optimization of the parameters, such as the content of graphene in the composite and the control in preparation, the electrocatalytic activity of $\mathrm{PtCo} / \mathrm{G}$ is expected to be remarkably enhanced. This work is anticipated to open a new possibility in the investigation of graphenesupported Pt-transition metal alloy catalysts and promote their practical application in energy conversion technologies.

This work was supported by the National Natural Science Foundation of China (50902070), the National High Technology Research and Development Program of China (2010AA0500293002), a Project Funded by the Priority Academic Program Development of Jiangsu Higher Education Institutions and Nanjing University of Science and Technology Research Funding (2011PYXM03).

1 Mu Y Y, Liang H P, Hu J S, et al. Controllable Pt nanoparticle deposition on carbon nanotubes as an anode catalyst for direct methanol fuel cells. J Phys Chem B, 2005, 109: 22212-22216

2 Qiu J D, Wang G C, Liang R P, et al. Controllable deposition of 
platinum nanoparticles on graphene as an electrocatalyst for direct methanol fuel cells. J Phys Chem C, 2011, 115: 15639-15645

3 Winter $M$, Brodd $\mathrm{R}$ J. What are batteries, fuel cells, and supercapacitors? Chem Rev, 2004, 104: 4245-4269

4 Qiao Y, Li C M. Nanostructured catalysts in fuel cells. J Mater Chem, 2011, 21: 4027-4036

5 Aricò A S, Srinivasan S, Antonucci V. DMFCs: From fundamental aspects to technology development. Fuel Cell, 2001, 1: 133-161

6 Basri S, Kamarudin S K, Daud W R W, et al. Nanocatalyst for direct methanol fuel cell (DMFC). Int J Hydrog Energy, 2010, 35: 7957-7970

7 Chan K Y, Ding J, Ren J W, et al. Supported mixed metal nanoparticles as electrocatalysts in low temperature fuel cells. J Mater Chem, 2004, 14: 505-516

8 Liu H S, Song C J, Zhang L, et al. A review of anode catalysis in the direct methanol fuel cell. J Power Sources, 2006, 155: 95-110

9 Lin Y H, Cui X L, Yen C H, et al. PtRu/carbon nanotube nanocomposite synthesized in supercritical fluid: A novel electrocatalyst for direct methanol fuel cells. Langmuir, 2005, 21: 11474-11479

10 Gu Y J, Wong W T. Nanostructure PtRu/MWNTs as anode catalysts prepared in a vacuum for direct methanol oxidation. Langmuir, 2006, 22: $11447-11452$

11 Wang C H, Dub H Y, Tsai Y T, et al. High performance of low electrocatalysts loading on CNT directly grown on carbon cloth for DMFC. J Power Sources, 2007, 171: 55-62

12 Wang J J, Yin G P, Zhang J, et al. High utilization platinum deposition on single-walled carbon nanotubes as catalysts for direct methanol fuel cell. Electrochim Acta, 2007, 52: 7042-7050

13 Alcaide F, Alvarez G, Cabot P L, et al. Testing of carbon supported Pd-Pt electrocatalysts for methanol electrooxidation in direct methanol fuel cells. Int J Hydrogen Energy, 2011, 36: 4432-4439

14 Jiang Q, Jiang L, Hou $\mathrm{H}$, et al. Promoting effect of $\mathrm{Ni}$ in PtNi bimetallic electrocatalysts for the methanol oxidation reaction in alkaline media: Experimental and density functional theory studies. J Phys Chem C, 2010, 114: 19714-19722

15 Wang Z B, Zhao C R, Shi P F, et al. Effect of a carbon support containing large mesopores on the performance of a $\mathrm{Pt}-\mathrm{Ru}-\mathrm{Ni} / \mathrm{C}$ catalyst for direct methanol fuel cells. J Phys Chem C, 2010, 114: 672-677

16 Chetty R, Xia W, Kundu S, et al. Effect of reduction temperature on the preparation and characterization of Pt-Ru nanoparticles on multiwalled carbon nanotubes. Langmuir, 2009, 25: 3853-3860

17 Zeng J H, Lee J Y. Effects of preparation conditions on performance of carbon-supported nanosize Pt-Co catalysts for methanol electrooxidation under acidic conditions. J Power Sources, 2005, 140: 268273

18 Zhao H, Li L, Yang J, et al. Synthesis and characterization of bimetallic Pt-Fe/polypyrrole-carbon catalyst as DMFC anode catalyst. Electrochem Commun, 2008, 10: 876-879

19 Antolini E, Salgado J R C, Gonzalez E R. Carbon supported Pt75M25 (M=Co, Ni) alloys as anode and cathode electrocatalysts for direct methanol fuel cells. J Electroanal Chem, 2005, 580: 145-154

20 Siracusano S, Stassi A, Baglio V, et al. Investigation of carbonsupported $\mathrm{Pt}$ and $\mathrm{PtCo}$ catalysts for oxygen reduction in direct methanol fuel cells. Electrochim Acta, 2009, 54: 4844-4850

21 Antolini E, Salgado J R C, Gonzalez E R. The methanol oxidation reaction on platinum alloys with the first row transition metals-the case of Pt-Co and -Ni alloy electrocatalysts for DMFCs: A short review. Appl Catal B: Environ, 2006, 63: 137-149

22 Lima F H B, Lizcano-Valbuena W H, Teixeira-Neto E, et al. Pt-Co/C nanoparticles as electrocatalysts for oxygen reduction in $\mathrm{H}_{2} \mathrm{SO}_{4}$ and $\mathrm{H}_{2} \mathrm{SO}_{4} / \mathrm{CH}_{3} \mathrm{OH}$ electrolytes. Electrochima Acta, 2006, 52: 385-393

23 Novoselov K S, Geim A K, Morozov S V, et al. Electric field effect in atomically thin carbon films. Science, 2004, 306: 666-669

24 Geim A K, Novoselov K S. The rise of graphene. Nat Mater, 2007, 6 : 183-191

25 Li D, Mueller M B, Gilje S, et al. Processable aqueous dispersions of graphene nanosheets. Nat Nanotechnol, 2008, 3: 101-105

26 Stankovich S, Dikin D A, Dommett G H B, et al. Graphene-based composite materials. Nature, 2006, 442: 282-286

27 Huang $\mathrm{H}$, Wang $\mathrm{X}$. Graphene nanoplate- $\mathrm{MnO}_{2}$ composites for supercapacitors: A controllable oxidation approach. Nanoscale, 2011, 3: 3185-3191

28 Xu C, Wang X, Zhu J W. Graphene-metal particle nanocomposites. J Phys Chem C, 2008, 112: 19841-19845

29 Huang H, Chen H, Sun D, et al. Graphene nanoplate-Pt composite as a high performance electrocatalyst for direct methanol fuel cells. J Power Source, 2012, 204: 46-52

30 Huang H, Sun D, Wang X. Low-defect MWNT-Pt nanocomposite as a high performance electrocatalyst for direct methanol fuel cells. J Phys Chem C, 2011, 115: 19405-19412

31 Li W Z, Liang C H, Qiu J S, et al. Carbon nanotubes as support for cathode catalyst of a direct methanol fuel cell. Carbon, 2002, 40: 791-794

32 Girishkumar G, Vinodgopal K, Kamat P V. Carbon nanostructures in portable fuel cells: Single-walled carbon nanotube electrodes for methanol oxidation and oxygen reduction. J Phys Chem B, 2004, 108: 19960-19966

33 Girishkumar G, Hall T D, Vinodgopal K, et al. Single wall carbon nanotube supports for portable direct methanol fuel cells. J Phys Chem B, 2006, 110: 107-114

34 Niyogi S, Bekyarova E, Itkis M E, et al. Solution properties of graphite and graphene. J Am Chem Soc, 2006, 128: 7720-7721

35 Dikin D A, Stankovich S, Zimney E J, et al. Preparation and characterization of graphene oxide paper. Nature, 2007, 448: 457460

36 Sharma S, Ganguly A, Papakonstantinou P, et al. Rapid microwave synthesis of $\mathrm{CO}$ tolerant reduced graphene oxide-supported platinum electrocatalysts for oxidation of methanol. J Phys Chem C, 2010, 114: 19459-19466

37 Li Y M, Tang L H, Li J H. Preparation and electrochemical performance for methanol oxidation of pt/graphene nanocomposites. Electrochem Commun, 2009, 11: 846-849

38 Nethravathi C, Anumol E A, Rajamathi M, et al. Highly dispersed ultrafine Pt and PtRu nanoparticles on graphene: Formation mechanism and electrocatalytic activity. Nanoscale, 2011, 3: 569-571

39 Choi S M, Seo M H, Kim H J, et al. Synthesis of surfacefunctionalized graphene nanosheets with high Pt-loadings and their applications to methanol electrooxidation. Carbon, 2011, 49: 904909

40 Dong L F, Gari R R S, Li Z, et al. Graphene-supported platinum and platinum-ruthenium nanoparticles with high electrocatalytic activity for methanol and ethanol oxidation. Carbon, 2010, 48: 781-787

41 Li Y J, Gao W, Ci L J, et al. Catalytic performance of Pt nanoparticles on reduced graphene oxide for methanol electro-oxidation. Carbon, 2010, 48: 1124-1130

42 Kovtyukhova N I, Ollivier P J, Martin B R, et al. Layer-by-layer assembly of ultrathin composite films from micron-sized graphite oxide sheets and polycations. Chem Mater, 1999, 11: 771-778

$43 \mathrm{Xu} \mathrm{C}, \mathrm{Wu} X$, Zhu J, et al. Synthesis of amphiphilic graphite oxide. Carbon, 2008, 46: 386-389

44 Xiong L, Kannan A M, Manthiram A. Pt-M ( $\mathrm{M}=\mathrm{Fe}$, Co, $\mathrm{Ni}$ and $\mathrm{Cu})$ electrocatalysts synthesized by an aqueous route for proton exchange membrane fuel cells. Electrochem Commun, 2002, 4: 898-903

45 Ferrari A C, Robertson J. Interpretation of Raman spectra of disordered and amorphous carbon. Phys Rev B, 2000, 61: 1409514107

46 Stankovich S, Dikin D A, Piner R D, et al. Synthesis of graphenebased nanosheets via chemical reduction of exfoliated graphite oxide. Carbon, 2007, 45: 1558-1565

$47 \mathrm{Fu} \mathrm{Y}$, Wang X. Magnetically separable $\mathrm{ZnFe}_{2} \mathrm{O}_{4}$-graphene catalyst and its high photocatalytic performance under visible light irradiation. Ind Eng Chem Res, 2011, 50: 7210-7218

48 Ray S C, Saha A, Basiruddin S K, et al. Polyacrylate-coated graphene-oxide and graphene solution via chemical route for various biological application. Diamond Relat Mater, 2011, 20: 449-453

49 Graf D, Molitor F, Ensslin K, et al. Spatially resolved raman spectroscopy of single- and few-layer graphene. Nano Lett, 2007, 7: 
238-242

50 Ferrari A C, Meyer J C, Scardaci V, et al. Raman spectrum of graphene and graphene layers. Phys Rev Lett, 2006, 97: 187401187404

51 Zheng S F, Hu J S, Zhong L S, et al. In situ one-step method for preparing carbon nanotubes and pt composite catalysts and their performance for methanol oxidation. J Phys Chem C, 2007, 111: 11174-11179

52 Mukerjee S, Srinivasan S, Soriaga M P, et al. Role of structural and electronic properties of Pt and Pt alloys on electrocatalysis of oxygen reduction. J Electrochem Soc, 1995, 142: 1409-1422

53 Cabeza G F, Légaré P, Castellani N J. Adsorption of CO on Co(0001) and Pt-Co(0001) surfaces: An experimental and theoretical study. Surf Sci, 2000, 465: 286-300

54 Wakisaka M, Mitsui S, Hirose Y, et al. Electronic structures of Pt-Co and Pt-Ru alloys for Co-tolerant anode catalysts in polymer electrolyte fuel cells studied by EC-XPS. J Phys Chem B, 2006, 110: 23489-
23496

55 Salgado J R C, Antolini E, Gonzalez E R. Carbon supported Pt-Co alloys electrocatalysts for as methanol-resistant oxygen-reduction direct methanol fuel cells. Appl Catal B: Environ, 2005, 57: 283-290

56 Pozio A, de Francesco M, Cemmi A, et al. Comparison of high surface Pt/C catalysts by cyclic voltammetry. J Power Sources, 2002, 105: 13-19

57 Liu B, Chen J H, Xiao C H, et al. Preparation of Pt/MgO/CNT hybrid catalysts and their electrocatalytic properties for ethanol electrooxidation. Energy Fuels, 2007, 21: 1365-1369

58 Krausa M, Vielstich W. Potential oscillations during methanol oxidation at Pt-electrodes Part 1: Experimental conditions. J Electroanal Chem, 1995, 399: 7-12

59 Chen J H, Wang M Y, Liu B, et al. Platinum catalysts prepared with functional carbon nanotube defects and its improved catalytic performance for methanol oxidation. J Phys Chem B, 2006, 110: 11775-11779

Open Access This article is distributed under the terms of the Creative Commons Attribution License which permits any use, distribution, and reproduction in any medium, provided the original author(s) and source are credited. 